\title{
NANOtECNOLogia no Ensino SECUNDÁRIO
}

\author{
JoÃo VALE ${ }^{1,2}$ E JoÃo PAIVA ${ }^{1 . *}$
}

\begin{abstract}
A 2010-2020 trará avanços significativos na area da nanotecnologia, a julgar pelo incremento do investimento científico e tecnológico nesta área. Discutir o nanomundo em sintonia com os programas curriculares de química será uma boa oportunidade para aumentar a literacia científica do aluno, mantendo-o cidadão informado e incrementando a motivação. Neste artigo divulgam-se as potencialidades de abordagem à nanotecnologia nos programas curriculares de química. Mencionam-se alguns conceitos e contextos relevantes em nanotecnologia para o $3 .^{\circ} \mathrm{Ciclo} \mathrm{e} \mathrm{Ensino} \mathrm{Secundário.}$ São apresentadas algumas recomendações pedagógicas. São inequívocas as vantagens pedagógicas da integração dos alunos nestas dinâmicas societais, capacitando-os para o confronto e a discussão sustentada em determinadas questões de índole cientifico e/ou tecnológico de "nano-assuntos".
\end{abstract}

\section{PotencialidADES DE ABORDAGEM DA NANOTECNOLOGIA NOS PROGRAMAS CURRICULARES DE QUIIMICA}

Quando Heraclito de Éfeso, nascido na Jónia (atual Turquia), referiu, num dos seus pensamentos, a palavra «mudança» - «Nada existe de permanente a não ser a mudança» (540 - 480 a.C.) - não teria, certamente, noção da dimensão dessa palavra em determinadas situações. Sinónimo de alteração, impõe-se esclarecer que essa alteração pode emergir de forma gradual, mas também de forma abrupta. A mudança pode ser pouco significativa, mas casos há em que essa modificação é mais do que sentida. Quando relacionada, por exemplo, com o tipo de materiais usados em utensílios, «mudança» é uma palavra sinónima da expressão «aparição de novas qualidades»... ou seja, uma nova era, entenda-se. $E$ foi em 1974 que o engenheiro Norio Taniguchi defendeu que o desenvolvimento da engenharia de precisão levaria ao aparecimento de uma nova era: a Era da Nanotecnologia [1].

Ao fazer-se uma questão individualizada a um grupo de 27 alunos a frequentar o $9 .^{\circ}$ ano de escolaridade - Já ouviste falar em nanotecnologia? Se sim, menciona o que pensas ser -

\footnotetext{
Centro de Investigação em Quimica, Departamento de Química e Bioquimica,

Faculdade de Ciências, Universidade do Porto, Rua do Campo Alegre, 687, P-4169-007 Porto

${ }^{2}$ Escola EBI/JI Padre Joaquim Flores

E-mail: jcpaiva@fc.up.pt
}

verificou-se que dez alunos já tinham ouvido falar. Destes, quatro referiram somente que já tinham ouvido falar e os restantes adiantaram um entendimento. As respostas dadas foram: «São tecnologias extremamente pequenas, são mais práticas mas é preciso habituar-se»; "Partículas muito pequenas com vida»; «Tecnologia em circunstâncias pequenas. Nano- muito pequeno»; «Tecnologia microscópica»; "Usada pelos robôs»; "Tentativa de construir materiais tecnológicos cada vez mais pequenos». Destas respostas conclui-se, no geral, que é feita uma nítida associação da palavra «nanotecnologia» a pequenez.

É possível abordar alguns conceitos ao nível do Ensino Secundário mas também ao nível do $3 .^{\circ}$ Ciclo do Ensino Básico numa dimensão nanotecnológica. Neste campo, e sobretudo no Secundário, convirá esclarecer que os químicos têm vindo a desenvolver um tipo de nanociência, considerando a sua intervenção ao nível da manipulação de um número elevadíssimo de nano-estruturas, as moléculas, mas, refira-se, sem aquele domínio individual que caracteriza a nanotecnologia [2]

Nas Orientações Curriculares para as Ciências Físicas e Naturais, os programas de Ciências nos três ciclos do Ensino Básico surgem organizados em quatro temas: Terra no Espaço, Terra em Transformação, Sustentabilidade na Terra e Viver melhor na Terra. Segundo estas guias, a exploração destes temas deve reger-se pela interdisciplinaridade em que «a interacção Ciência - Tecnologia - Sociedade - Ambiente deverá constituir uma vertente integradora e globalizante da organização e da aquisição dos saberes científicos» [3]. Os alunos poderão aceder a produtos da Ciência e compreender as potencialidades e limites da Ciência e suas aplicações na Sociedade.

É necessário estar atento às atualizações/novidades a nível da Ciência e Tecnologia para que todo o cidadão ao ser confrontado na praça pública com questões de índole cientifico e/ ou tecnológico possa emitir opinião. É certo, neste âmbito, que o professor poderá focar várias situações, mas sempre em alerta quanto à profundidade a usar.

O programa de Física e Química A $10 .^{\circ}$ ano [4] propõe a consecução de vários objetivos de aprendizagem na esfera da Unidade 2 - Na atmosfera da Terra: radiação, matéria e estrutura. Interpretar o modo como atua um filtro solar é exemplo de um objetivo que pode ser extensível à potencialidade dos fulerenos como limitadores óticos.

No programa de Física e Química A 11. ${ }^{\circ}$ ano, toda a Unidade I, Produção e controlo - a síntese industrial do amoníaco, desenvolve-se em torno do amoníaco. Assinala-se, neste contexto, os argumentos a serem usados pelos alunos na apreciação a esta 
Unidade. Os alunos devem usar «argumentos técnico-científicos, sociais e económicos e (...) reconhecer (...) na actividade industrial um dos elementos caracterizadores da cultura actual» [5]. Neste sentido, debater produtos da nanotecnologia, ao nível de catalisadores, com potencial nesta indústria, mostra-se pertinente.

Já a Unidade II, Da Atmosfera ao Oceano: Soluções na Terra e para a Terra, têm o seu ônus na água. Ao longo da Unidade, a interpretação da qualidade da água como dependente do «uso de alguns artefactos tecnológicos» pode ser aproveitada para debate de soluções nanotecnológicas neste domínio.

Para o $12 .^{\circ}$ ano de Química, e atendendo ao respetivo programa [6], na Unidade I, quando se debatem os metais, designadamente as ligas metálicas, a possibilidade de extensão à nanotecnologia assume-se como tarefa quase que impossível de não realizar. Reconhecer a importância das ligas metálicas em determinadas utilizações, pelo facto de se poder controlar a sua composição e, consequentemente, "desenhar" as suas propriedades, especificamente identificar a composição e conhecer domínios de aplicação da solda, são objetivos pedagógicos estipulados no programa e cuja abordagem numa dimensão nanotecnológica permitirá a sua concretização. É saudável debater uma temática atual em sintonia com o cumprimento de objetivos pedagógicos estipulados no programa.

Ainda na esfera do $12 .^{\circ}$ ano de Química, mas agora na Unidade 3 , quando se debatem os Novos Materiais, poder-se-á, mais uma vez, mergulhar na nanotecnologia. O professor poderá frisar o impacto da nanotecnologia na produção/viabilização de Novos Materiais que podem, por si só, substituir materiais pouco aconselháveis do ponto de vista ambiental ou servir de matéria-prima para a concretização de Novos Materiais, especificamente biomateriais. É possível atingir determinados objetivos programáticos abordando a nanotecnologia. Reconhecer os compósitos como um grupo que se insere na categoria de biomateriais; distinguir as duas fases de um compósito: a fase contínua (matriz),

escolhida de forma a conferir a maleabilidade ou ductilidade, e a fase descontínua (fase dispersa ou fase de reforço), escolhida de forma a conferir resistência, são exemplos.

Alguns conceitos E CONTEXtos RELEVANTES EM NANOTECNOLOGIA PARA O ENSINO SECUNDÁRIO

Uma primeira abordagem à nanotecnologia pode ser feita já no $7 .^{\circ}$ ano de escolaridade. Tal referência passa por mencionar o desenvolvimento de um material que possibilitaria a união do planeta Terra à Estação Orbital Internacional [7]. Esse material funcionaria como uma corda servindo de suporte ao movimento de um elevador, Figura 1 , cuja concretização abriria uma janela de oportunidades para o fluxo de objetos e pessoas.

Como se trata de um assunto que normalmente suscita muita curiosidade pelos alunos, o professor poderá adiantar o carbono como fundamental na constituição de tubos que serão o berço desse material e mostrar imagens, Figura 2, desses tubos de carbono frisando que as suas dimensões

Tabela 1 - Propriedades de nanotubos de carbono, aço e alumínio $[9,10]$

\begin{tabular}{|c|c|c|c|}
\hline & $\begin{array}{c}\text { Resistência à tração/ } \\
\mathrm{GPa}\end{array}$ & $\begin{array}{c}\text { Módulo de Young/ } \\
\mathrm{GPa}\end{array}$ & $\begin{array}{c}\text { Densidade/ } \\
\mathrm{g} \mathrm{cm}^{-3}\end{array}$ \\
\hline $\begin{array}{c}\text { SWNT } \\
\begin{array}{c}\text { single-walled carbon } \\
\text { nanotubes) }\end{array}\end{array}$ & $20-100$ & $500-1500$ & $\approx 1$ \\
\hline $\begin{array}{c}\text { MWNT } \\
\text { (multi-walled carbon } \\
\text { nanotubes) }\end{array}$ & $10-60$ & $200-1000$ & 2,16 \\
\hline $\begin{array}{c}\text { Aço }(0,2 \% \mathrm{C}) \\
\text { Alumínio }\end{array}$ & 0,380 & 210 & 7,86 \\
\hline
\end{tabular}

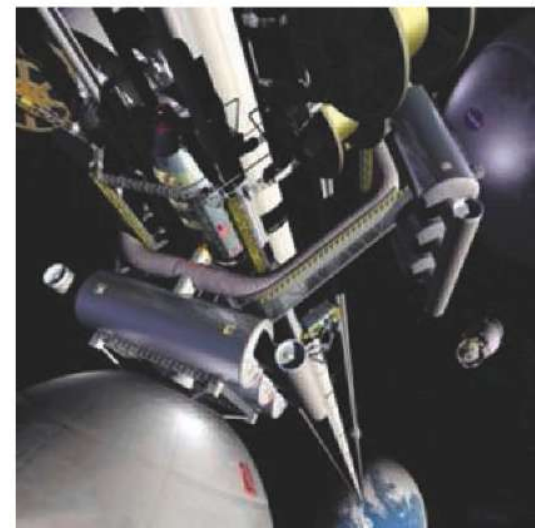

Figura 1 - Imagem virtual de um elevador rumo à Estação Orbital em termos de diâmetro são cerca de 1000000 de vezes inferior ao milímetro... daí chamarem-se nanotubos.

Na Tabela 1 apresentam-se algumas propriedades dos nanotubos de carbono em comparação com dois outros materiais: o aço e o alumínio.

Sendo $07 .^{\circ}$ ano de escolaridade ano de iniciação dos alunos às Ciências Físico-Químicas, convirá surpreender os alunos com diversos projetos de centros portugueses. O CeNTI, por exemplo, apresentou, no final de 2010 , dez projetos inovadores desenvolvidos em associação com outras entidades nacionais. Tais projetos incidiram sobre diversas áreas: saúde e bem-estar, desporto e lazer, proteção individual, segurança, automóvel, aeronáutica, construção e arquitetura, energias renováveis e fotovoltaica, entre outras. Alguns desses projetos [11]: peúgas com capacidade de monitorizar os batimentos cardíacos; Nanoleather - desenvolvimento de couros biocoloridos, reflectores de luz e antimicrobianos; luvas técnicas funcionalizadas à escala nanométrica; ladrilhos com libertação lenta de 
fragrâncias; toalha easy-clean. A toalha easy-clean - um tecido à prova de nódoas - possui a capacidade de repelir a sujidade. $O$ diretor do $\mathrm{CeNTI}$, em entrevista aos media, sublinhou o papel importante dos nanomateriais na conceção de um material que impeça os líquidos de penetrar no tecido. Realçou que o tecido demonstrara bons resultados em contacto com vinho, café e óleo, e resistira a várias lavagens. Dependendo da sensibilidade dos alunos o professor poderá adiar este assunto para $08 .^{\circ}$ ano pois é nesse ano que é introduzido o nanómetro.

No $9 .^{\circ}$ ano de escolaridade, aquando da referência às substâncias covalentes, especificamente o diamante e a grafite, o professor pode questionar os alunos, ou mesmo autointerrogar-se em voz alta, sobre a possibilidade de existência de outras formas de carbono. Neste seguimento pode informar, entre outras, que é possível encontrar moléculas constituídas unicamente por carbono e exemplificar com o fulereno $\mathrm{C}_{60}$. Poderá acrescentar que esta molécula, inicialmente, foi batizada como buckminsterfulereno, em homenagem ao arquiteto americano $B$. Fuller, responsável pela invenção dos domos geodésicos e que perante um nome algo extenso, a molécula $C_{60}$ é comummente conhecida como buckyball, em português "futeboleno», devido à sua semelhança com uma bola de futebol, Figura 3 esquerda.

Poderá ainda mencionar algumas aplicações dos fulerenos: matéria-prima para a produção de diamantes ou materiais super-resistentes [13] e lubrificantes [14]. No caso dos lubrificantes, acrescentar que os nanofluidos podem aumentar significativamente a condutividade térmica dos habituais fluidos usados em máquinas, Figura 4.

Para $010 .^{\circ}$ ano, no âmbito da Unidade 2 - Na atmosfera da Terra: radiação, matéria e estrutura, poder-se-ão fazer duas observações. A primeira, que salienta a potencialidade dos fulerenos como limitadores ópticos [16], verificando-se que, quando uma certa quantidade de luz visível incide no fulereno $\mathrm{C}_{60}$, ocorre a formação da espécie excitada ${ }^{*} \mathrm{C}_{60}$. Como a espécie
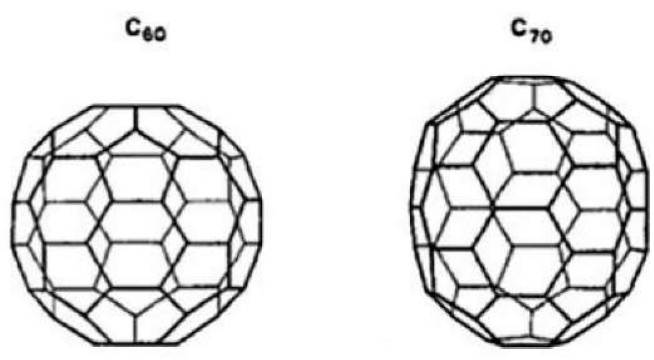

$C_{70}$

Figura 3 - Estrutura de alguns fulerenos: $C_{60^{\prime}} C_{70}$ e $C_{76}[12]$

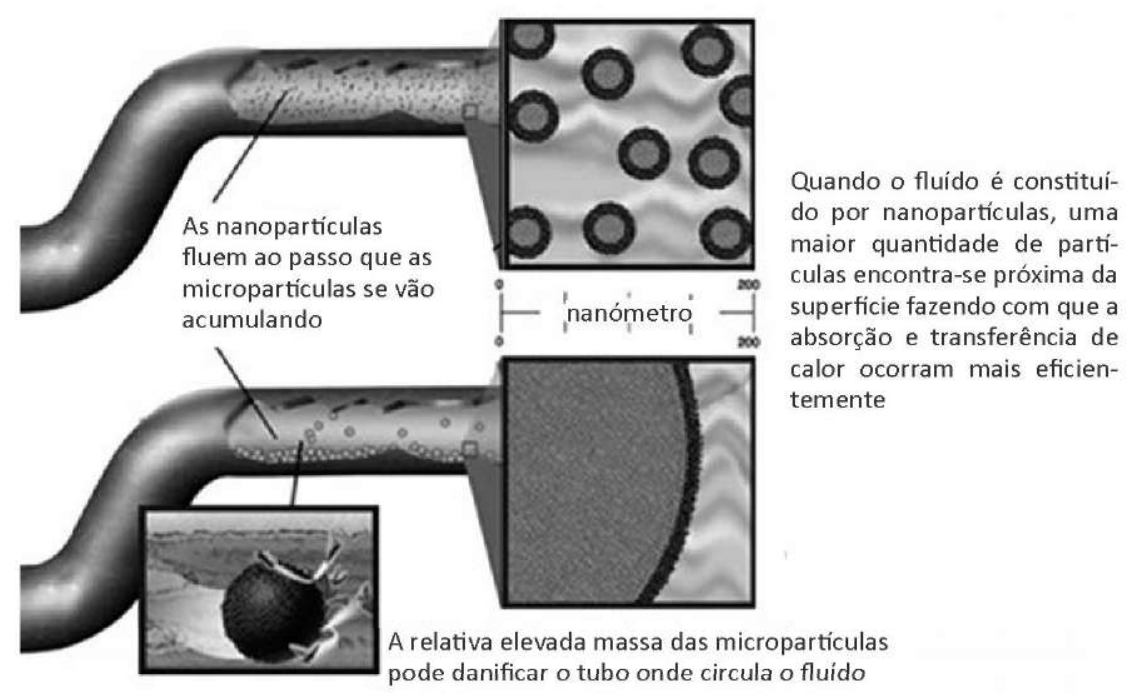

Figura 4-Nanopartículas (em cima) e micropartículas (em baixo) no interior de um tuboinfluência da massa na deterioração do tubo e absorção de calor [15]

${ }^{*} \mathrm{C}_{60}$ absorve mais luz que a anterior, assiste-se a uma alteração de cor... a solução torna-se mais preta - facto que pode ser aproveitado para elaborar filmes para posterior deposição em equipamentos sensíveis a superexposições acidentais de raios de luz, Figura 5. A segunda, que constata a aplicação de nanopartículas de óxido de zinco na produção de cremes solares - a utilização de nanopartículas de óxido de zinco na produção de cremes protetores solares torna o creme transparente, ou seja, extingue o branco característico dos cremes.

A Unidade I do programa de Física e Química A $11 .^{\circ}$ ano, Produção e controlo - a síntese industrial do amoníaco, desenvolve-se, como citado anteriormente, em torno do amoníaco. O processo de Haber-Bosch remonta ao século passado. Trata-se de um processo industrial catalítico, em que o ferro é catalisador, que visa a obtenção de amoníaco.

Investigações recentes [17] mostraram que a atividade do catalisador de ferro para síntese do amoníaco pode ser superada em $33,5 \%-37,6 \%$ pelo catalisador de ruténio, para condições de reação $T=375-400^{\circ} \mathrm{C}$ e $p=10 \mathrm{MPa}$. Por outro lado, ao serem testados vários catalisadores de ruténio no processo de síntese do amoníaco, verificou-se que aquele que possuía fulerenos era o mais eficiente, Figura 6.

Urge abordar os fulerenos, referindoos como uma forma alotrópica do carbono, e citar outros exemplos de aplicação citados neste artigo.

Já a Unidade 2 tem a sua essência na água. A água, sendo um bem

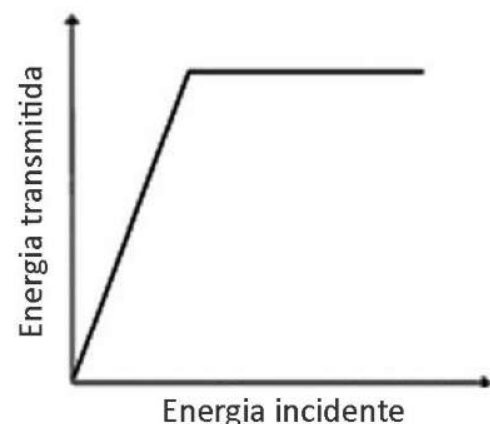

Figura 5 - Representação do comportamento de um limitador ótico 
indispensável ao planeta, insta ao desenvolvimento de métodos para a sua purificação. Um método recente consiste em recorrer à nanotecnologia para que, de forma mais rápida $e$ eficiente, se obtenha água doce a partir de água do mar. Os métodos tradicionais exigem uma certa pressão para que a água do mar atravesse um filtro, onde o sal fica retido, e essa pressão aumenta à medida que o sal se deposita nesse filtro. Recorrendo a simulações de dinâmica molecular constatou-se que 0 recurso a nanotubos de nitreto de boro poderia levar à eliminação de $100 \%$ do sal em águas com o dobro da quantidade de sal da água do mar, além de permitir a fluidez da água com o quádruplo da velocidade [19].

Intitulada Metais e Ligas Metálicas, a Unidade I de Química do $12 .^{\circ}$ ano começa por abordar os metais. Recordando que a palavra «metal» deriva de métallon (que significa mina, em grego) e apresenta, nos nossos dias, vários significados, conforme o contexto em que é utilizada, os metais assumem uma estrutura tal que viabilizam a formação de ligas metálicas, normalmente misturas homogéneas de um metal com um ou mais elementos metálicos ou não-metálicos. A solda usada em circuitos eletrónicos consiste numa liga de $\mathrm{Sn} / \mathrm{Pb}$ com temperatura de fusão que ronda os $183^{\circ} \mathrm{C}$, dependendo da sua constituição. São conhecidos os efeitos prejudiciais à saúde e ambiente pelo chumbo. A impossibilidade de usar ligas de $\mathrm{Sn} / \mathrm{Ag}$ nesta situação, motivo da sua temperatura de fusão que ronda os $222^{\circ} \mathrm{C}$, pode ser ultrapassada por recurso à nanotecnologia. A conceção de diferentes diâmetros das nanopartículas ocasiona diferentes pontos de fusão. O tamanho das nanopartículas de

Tabela 2 - Ponto de fusão em função do tamanho de nanopartículas de Sn96,5/Ag3,5 [20]

\begin{tabular}{|c|c|}
\hline $\begin{array}{c}\text { Diâmetro de } \\
\text { nanoparticulas de } \\
\text { Sn96,5/Ag3,5 } \mathrm{nm}^{-1}\end{array}$ & Ponto de fusão/ ${ }^{\circ} \mathrm{C}$ \\
\hline 64 & 220,0 \\
\hline 24 & 209,5 \\
\hline 17 & 206,0 \\
\hline 10 & 194,3 \\
\hline
\end{tabular}

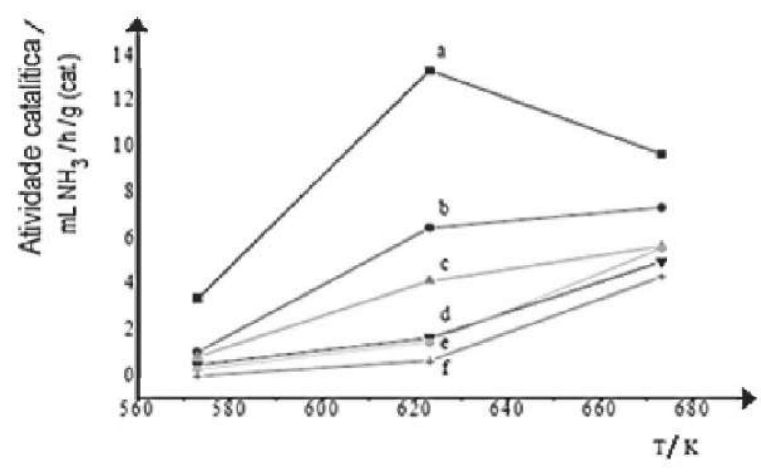

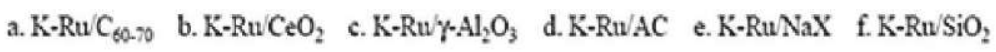

Figura 6 - Desempenho de diferentes catalisadores de ruténio na síntese do amoníaco em $\mathrm{mL}$ de $\mathrm{NH}_{3} /$ hora/grama de catalisador [18]

uma liga metálica $\mathrm{Sn} / \mathrm{Ag}(96,5 \% \mathrm{Sn}$ e $3,5 \% \mathrm{Ag}$ ) determina o seu ponto de fusão (Tabela 2).

Numa área de grande investigação, motivada, em primeiro grau, pela escassez de recursos energéticos não renováveis, pode referir-se o uso de nanotubos de carbono como elétrodos em baterias de iões lítio [21]. Segundo o MIT (Massachusetts Institute of Technology), investigadores deste centro terão usado nanotubos de carbono como elétrodo positivo numa bateria de iões-lítio, constatando um aumento de dez vezes na quantidade de energia a debitar em relação à bateria normal. Além disso, a bateria foi capaz de armazenar cinco vezes mais energia do que um ultracondensador convencional, Figura 7. A elevada área superficial e condutividade dos nanotubos terão sido as propriedades que desafiaram os investigadores a usá-los como elétrodos.

Ainda na esfera do $12 .^{\circ}$ ano de Química, mas agora na Unidade 3 , quando se debatem os Novos Materiais, poder-se-á mais uma vez mergulhar na nanotecnologia.

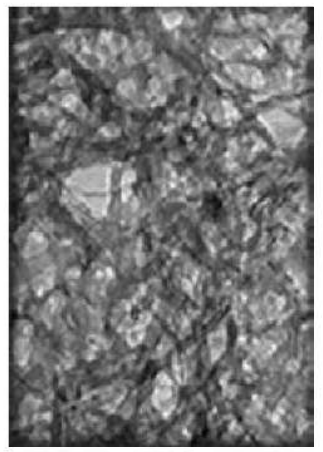

Figura 7 - Os espaços entre os nanotubos podem armazenar iões-lítio [21]
Recentemente, o Centro de Tecnologia Mecânica e Automação da Universidade de Aveiro (TEMA), em parceria com o Centro de Investigação em Materiais Cerâmicos e Compósitos (CICECO) e o Georgia Institut of Technology, desenvolveu um novo nanocompósito para aplicações biomédicas que apresenta uma elevada resistência mecânica e permite a criação de interfaces biocompatíveis com o osso circundante e consequentemente crescimento ósseo no nanocompósito [22]. Trata-se da hidroxiapatite modificada com poli(metacrilato de metilo) e reforçada com nanotubos de carbono. Este nanocompósito consegue melhores propriedades mecânicas quando a concentração em massa de nanotubos de carbono em relação à mistura hidroxiapatite-poli(metacrilato de metilo) é $0,1 \%$.

Nanocompósitos de hidroxiapatite também já se revelaram eficientes em implantes para restauração de dentes [23] e biomateriais à base de fosfato de cálcio e têm-se mostrado importantes na reparação de dentes devido à sua biocompatibilidade e bioatividade [24]. A hidroxiapatite, $\mathrm{Ca}_{10}\left(\mathrm{PO}_{4}\right)_{6}(\mathrm{OH})_{2}$, é o principal componente mineral dos dentes e ossos, sendo o produto final estável na precipitação de iões fosfato e cálcio em soluções neutras ou básicas $\left(7 \leq \mathrm{pH} \leq 9 ; T=37^{\circ} \mathrm{C}\right)$. $\mathrm{A}$ camada remineralizada comporta-se exatamente como material próprio do dente.

A procura de materiais que se apresentem o mais próximo possível dos tecidos ósseos é um dos grandes desafios para o desenvolvimento de ossos 
artificiais. Exige-se uma réplica ao nível das propriedades biológicas e mecânicas - condição de extrema importância para sucesso na implantação.

Foram estudadas as vantagens do uso de MWNT em associação ao polímero PmPV - poli $(m$-fenilenovinileno-co-2,5-dioctoxi-p-fenilenovinileno) [25]. Constatou-se que o compósito MWNT-PmPV apresenta uma condutividade elétrica 8 vezes superior quando comparado ao PmPV. Este compósito, ao ser usado em LEDs, díodos emissores de luz, leva a que ocorra um aumento significativo do brilho. A incorporação de MWNT no poliuretano também foi estudada [26]. Sendo o poliuretano combustível, parece ter sido encontrada uma forma capaz de contrariar esta propriedade. A solução passa pela inclusão de 1-2\% em massa de MWNT no compósito PU-MWNT. Tal procedimento reduz em cerca de $50 \%$ a temperatura de ignição.

A importância da nanotecnologia em diversos domínios poderá ficar demonstrada com apelo à Tabela 3 .

Na área da computação, o ónus reside na construção de nanomáquinas. Em maio de 2010, a Nature publicou um artigo intitulado «Molecular robots guided by prescriptive landscapes» [28], no qual cientistas de universidades americanas terão criado uma molécula... robotizada. Apelidada de aranha molecular, a molécula moveu-se ao longo de ADN, sendo capaz de virar e parar.

\section{ReCOMENDAÇÖES}

Embora vários estudos de opinião pública sobre a nanotecnologia apontem para um público bastante entusiasta por parte dos EUA, a captação pública da nanotecnologia na Europa é mais contida [29]. Facto assente é o incremento no investimento na área da nanotecnologia que se tem verificado na generalidade dos países. Os cientistas terão encontrado um campo de investigação que semeia a realização do inimaginável e os governos começam a acreditar que essa realização será vantajosa [30]. Pensa-se que a década de 2010-2020 trará avanços significativos na área da nanotecnologia, Figura 8. A discussão desta área em sintonia com os programas curriculares será uma forma de ir preparando o aluno, enquanto cidadão, para que ao ser confrontado na praça pública com determinadas questões de índole cientifico e/ou tecnológico possa emitir opinião. Assim, recomenda-se:
- no Ensino Básico, 7. ${ }^{\circ}$ ano de escolaridade: aquando do estudo do Universo fazer referência ao facto da NASA estar empenhada no desenvolvimento de um material suficientemente resistente para ligar o planeta Terra à Estação Orbital Internacional. Dessa forma, poderá discutir com os alunos o berço desse material nas suas dimensões transversais e comparar algumas das suas propriedades com materiais comuns, como o aço e o alumínio. (Dependendo da sensibilidade dos alunos o professor poderá adiar este assunto para $\circ 8 .^{\circ}$ ano pois é nesse ano que é introduzido o nanómetro);

- no Ensino Básico, 9. ano de escolaridade: aquando do estudo das substâncias covalentes, provocar o seguinte: Vimos que o diamante e a grafite são constituídos unicamente por átomos de carbono e que dizem respeito a substâncias covalentes.

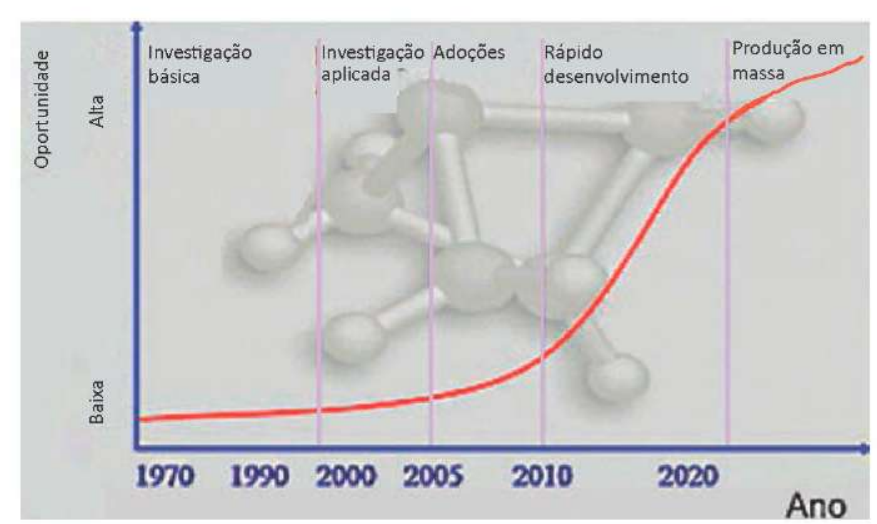

Figura 8 - Previsão da evolução da nanotecnologia [31]

Tabela 3 - Áreas de maior impacto da nanotecnologia [27]

\begin{tabular}{|c|c|c|}
\hline Área & Aplicaçōes & Observações \\
\hline Materiais & $\begin{array}{l}\text { Nanocristais, nanopartículas, nanotubos } \\
\text { e monocamadas em automontagem }\end{array}$ & $\begin{array}{l}\text { Dispositivos/sistemas que conseguem explorar a nano-escala } \\
\text { mecânica, elétrica, magnética, atómica e os efeitos quânti- } \\
\text { cos para melhorar a funcionalidade }\end{array}$ \\
\hline Energia & $\begin{array}{l}\text { Baterias avançadas, células fotovoltaicas, células de com- } \\
\text { bustível e microfontes de energia }\end{array}$ & $\begin{array}{l}\text { Dispositivos/sistemas que aumentam o armazenamento de } \\
\text { energia e a sua distribuição através do controlo de materiais } \\
\text { e superficies ao nivel atómico }\end{array}$ \\
\hline Biotecnologia & $\begin{array}{l}\text { Biochips, biossensores, descoberta e distribuição de } \\
\text { fármacos, diagnóstico e nanocirurgia }\end{array}$ & $\begin{array}{l}\text { Dispositivos/sistemas que localizam ou identificam proces- } \\
\text { sos biológicos para melhorar o diagnóstico, a síntese e distri- } \\
\text { buição de fármacos }\end{array}$ \\
\hline Computação & $\begin{array}{l}\text { Computadores quânticos, computadores moleculares, } \\
\text { computadores óticos, computadores de ADN }\end{array}$ & $\begin{array}{l}\text { Sistemas que pretendem utilizar métodos alternativos aos } \\
\text { eletrónicos para representar e processar dados mais rapida- } \\
\text { mente ou de novas formas }\end{array}$ \\
\hline Eletrónica & $\begin{array}{l}\text { Bens inteligentes, nano-eletrónica, eletrónica pervasiva e } \\
\text { sistemas de imagiologia }\end{array}$ & $\begin{array}{l}\text { Os sistemas eletrónicos (ou óticos) têm dimensões tão re- } \\
\text { duzidas que são praticamente invisíveis e podem ser usados } \\
\text { em qualquer local e de quaisquer formas }\end{array}$ \\
\hline
\end{tabular}


Existirão moléculas constituídas unicamente por átomos de carbono? No seguimento desta questão exemplificar com os fulerenos, mostrar imagens e enumerar algumas aplicações.

- no Ensino Secundário, $10{ }^{\circ}$ ano de escolaridade: aquando do estudo da radiação solar focar a potencialidade dos fulerenos como limitadores óticos e a vantagem estética do uso de nanopartículas de óxido de zinco em protetores solares.

- no Ensino Secundário, $11 .^{\circ}$ ano de escolaridade: aquando da discussão acerca do processo de Haber-Bosch, debater o possivel uso de catalisadores de ruténio na produção de amoníaco e, mais uma vez, debater os fulerenos; e aquando da discussão do papel da água na vida do planeta Terra, confrontar com um método que permite obter água potável a partir de água do mar por recurso à nanotecnologia.

- no Ensino Secundário, $12 .^{\circ}$ ano de escolaridade: aquando da discussão dos metais/ligas metálicas, debater a liga $\mathrm{Sn} / \mathrm{Ag}$ como possivel candidata a substituir a liga $\mathrm{Sn} / \mathrm{Pb}$ nos circuitos eletrónicos; e aquando da discussão dos Novos Materiais, frisar exemplos de aplicação de nanocompósitos. O uso de nanotubos de carbono como elétrodos em baterias de iões lítio poderá ser inserido na temática Energia e Recursos Energéticos

\section{REFERÊNCIAS}

[1] Morgado, J. (2010). Boletim da SPQ Vol. 116. Janeiro - Março. p. 116.

[2] Fiolhais, C. - «Nanotecnologia: o futuro vem aíl». [online] [consultado em 2 de janeiro de 2011]. Disponível em: https://estudogeral.sib.uc.pt/jspui/ bitstream/10316/12377/1/NANOTECNOLOGIA.pdf.

[3] Galvão, C. et al. (2001) - "Ciências Físicas e Naturais - Orientações Curriculares $3 .^{\circ}$ ciclo». Ministério da Educação, Departamento da Educação Básica. p. 9.

[4] Martins, I. et al. (2001) - «Programa de Física e Química A $100^{\circ}$ ano». Ministério da Educação, Departamento do Ensino Secundário.

[5] Martins, I. et al. (2003) - «Programa de Física e Química A $11 .{ }^{\circ}$ ou $12 .{ }^{\circ}$ anos». Curso Cientifico-Humanístico de Ciências e Tecnologias. Ministério da Educação, Departamento do Ensino Secundário p. 2.

[6] Martins, I. et al. (2004) - "Programa de Química $12 .^{\circ}$ ano». Curso Cientifico-Humanístico de Ciências e Tecnologias. Ministério da Educação, Direção Geral de Inovação e de Desenvolvimento Curricular.

[7] Zyga, L. (2009) - «Long, Stretchy Carbon Nanotubes Could Make Space Elevators Possible». Physorg.com. [online] [consultado em 2 de janeiro de 2011]. Disponível em: http://www. physorg.com/news151938445.html.

[8] Reilly, R. (2007). Journal of Nuclear Medicine. [online] [consultado em 2 de janeiro de 2011]. Disponível em: http://jnm.snmjournals.org/content/48/7/1039. full.

[9] Paiva, M. [online] [consultado em 2 de janeiro de 2011]. Disponível em: http://www.dep.uminho.pt/mcpaiva/ pdfs/PED/0607F01.pdf.

[10] Aços Salgueiro (2010) - [online] [consultado em 2 de janeiro de 2011]. Disponivel em: http://www.acosalgueiro. com/ASPX/mundodoaco.aspx.

[11] Soares, R. (2010) - «CeNTI apresentou dez projectos inovadores desenvolvidos em Portugal». Público. 16 de Dezembro. p. 35

[12] Santos, M. (1996). Revista Portuguesa de Química. N. ${ }^{\circ} 3$. p. 3.

[13] Regueiro, M. (1992). Advanced Materials. Vol. 4. Artigo 6. Weinheim: Verlag GmbH \& Co. KGaA. p. 438.

[14] Ginzburg, B. et al. (2002). Russian Journal of Applied Chemistry. Vol. 75. N. ${ }^{\circ}$ 8. p. 1330.

[15] Choi, S. (2005) - «Nanofluids Could Make Cool Work of Hot Truck Engines». Argonne National Laboratory. [online] [consultado em 2 de janeiro de 2011]. Disponivel em: http://nano. anl.gov/news/highlights/2005_choi. html.

[16] Filho R. (1996) - "Os Fulerenos e a sua espantosa geometria molecular». Química Nova na Escola. [online] [consultado em 2 de janeiro de 2011]. Disponivel em: http://qnesc.sbq.org. br/online/qnesc04/atual.pdf.

[17] Pan C. et al. (2011). Chinese Journal of Chemical Engineering. Vol. 19. N. ${ }^{\circ}$ 2. p. $273-277$.

[18] Wei, G. et al. (1999). Chinese Chemical Letters. [online] [consultado em 2 de janeiro de 2011]. Disponível em: http://www.imm.ac.cn/journal/ ccl/1005/100530-0433-98563-p2.pdf.
[19] Unicamp (2011). «Dessalinização: a nanotecnologia oferece método rápido e eficiente para transformar a água do mar em água doce». [online] [consultado em 2 de janeiro de 2011]. Disponivel em: http://lqes.iqm.unicamp.br/canal_cientifico/lqes_news/ lqes_news_cit/lqes_news_2009/lqes_ news_novidades_1334.html.

[20] Jiang, H. et al. (2007). Electronic Components and Technology Conference. [online] [consultado em 2 de janeiro de 2011]. Disponível em: http:// ecadigitallibrary.com/pdf/57thECTC/ s02p2li.pdf.

[21] Bourzac, K. (2010). Technology Review. [online] [consultado em 2 de janeiro de 2011]. Disponível em: http://www.technologyreview.com/ energy $/ 25634 /$ ?ref=rss.

[22] Singh, M. et al. (2008). Advanced Functional Materials. [online] [consultado em 2 de janeiro de 2011]. Disponível em: http://www.ua.pt/uaonline/upload/med/med_901.pdf

[23] Sung, Y. et al. (2007). Nanotechnology. Vol. 18. N. ${ }^{\circ}$ 6. p. 65602-65607.

[24] Chow, L. et al. (2009). Journal of Materials Science: Materials in Medicine. [online] [consultado em 2 de janeiro de 2011]. Disponivel em: http:// www.ncbi.nlm.nih.gov/pmc/articles/ PMC3056554/.

[25] Monthioux, M. et al. (2001) - Springer Handbook of Nanotechnology: Introduction to Carbon Nanotubes. New York: Springer Science \& Business Media, Inc. pp. 80-95.

[26] Mittal, V. (2010) - Polymer Nanotube Nanocomposites: Synthesis, Properties, and Applications. Massachusetts: Scrivener. p. 157.

[27] Roughley, D. (2004) - «Nanotechnology in a Nutshell». p. 2. [online] [consultado em 2 de janeiro de 2011]. Disponível em: http://www.smallcapmedia.com/pdf/Nanotechfinal.pdf.

[28] Lund, K. et al. (2010). Nature. Vol. 465. N. ${ }^{\circ}$ 7295. p. 206-210.

[29] Burri, R. e Bellucci, S. (2008). Journal of Nanoparticle Research. Springer Science \& Business Media B.V. p. 387.

[30] Gannon, F. (2003) - «Nano-nonsense». EMBO reports. [online] [consultado em 4 de janeiro de 2011]. Disponivel em: http://www.nature. com/embor/journal/v4/n11/full/embor7400014.html.

[31] Technolytics (2001) - [online] [consultado em 4 de janeiro de 2011]. Disponível em: http://www.technolytics. com/Technology $\% 20$ and $\% 20$ our $\% 20$ Future.pdf. 